\section{NưN Kastamonu Eğitim Dergisi Kastamonu Education Journal}

Eylül 2019 Cilt:27 Sayı:5

kefdergi.kastamonu.edu.tr
Başvuru Tarihi/Received: 05.10.2018

Kabul Tarihi/Accepted: 05.12.2018

DOI: $10.24106 /$ kefdergi.3381

\title{
Yükseköğretim Kurumlarında Artırılmış Gerçeklik Uygulamalarına Yönelik Yapılmış Araştırmaların İ́celenmesi
}

\section{Investigation of Researches on Augmented Reality Applications in Higher Education Institutions}

\author{
Yıldız ÖZAYDIN AYDOĞDU ${ }^{1}$, Selami ERYILMAZ²
}

\begin{abstract}
Öz
Bu çalışmanın amacı, Türkiye ve yurt dışında yükseköğretimde artırılmış gerçeklik üzerine yapılan çalışmaların incelenmesidir. Bu amaç doğrultusunda Eric ve Academic Search Complete veri tabanlarında bulunan 47 makaleye, ULAKBIM veri tabanında bulunan bir makaleye ve YÖK tez tarama motorunda bulunan 11 teze ulaşılmış, bu çalışmalardan 55'ine erişilebilmiştir. Literatür taraması yükseköğretim kurumlarında 2015-2018 yıllarında yapılan araştırmalara yönelik yapılmıştr. Erişilen çalışmalar araştırmacılar tarafindan araştırma yöntemi, örneklem büyüklükleri, öğrenme alanları, kullanılan AG teknolojileri, veri toplama araçları ve bağımlı değişkenler açısından incelenmiştir. Incelemeler sonucunda elde edilen verilere yönelik betimsel analizler yapılmıştır. Analiz sonuçlarına göre frekans ve yüzde tablolarına yer verilerek Türkiye ve yurt dışında yapılan araştırmalara yönelik karşılaştırmalar yapılmıştır. Elde edilen verilere göre; Türkiye de en çok karma yöntemin, yurt dışında ise nicel araştırma yöntemlerinin kullanıldığı, en çok tercih edilen örneklem büyüklüğünün 30-100 değerleri arasında olduğu, Türkiye de beş farklı öğrenme alanında çalışmalar yürütülürken yurt dışında 10 alanda çalışmalar yürütüldüğü, mobil arttılmış gerçeklik teknolojilerinin en çok tercih edilen AG teknolojisi olduğu, veri toplama da anketlerin sıklıkla kullanıldığı, başarı ve tutum bağımlı değişkenlerinin en çok tercih edilen bağımlı değişkenler olduğu sonucuna ulaşılmıştır.
\end{abstract}

Anahtar Kelimeler: artırılmış gerçeklik, yükseköğretim, araştırma eğilimleri

\section{Abstract}

The aim of this study is to examine the work done on the augmented reality in higher education in Turkey and abroad. For this purpose, 47 articles in Eric and Academic Search Complete databases, one article in ULAKBIM database and 11 articles in YÖK thesis scanning engine were reached and 55 of these articles were accessed. The literature review was conducted for the researches conducted in the higher education institutions in 2015-2018. The researches were investigated by researchers in terms of research method, sample sizes, learning areas, AR techniques used, data collection tools and dependent variables. Descriptive analysis was performed for the data obtained as a result of the examinations. According to the results table giving place to the frequency and percentage comparisons made in Turkey and abroad for the research was conducted. According to the obtained data; Turkey is the most mixed methods, which uses quantitative research methods abroad, to be among the most preferred 30-100 value of the sample size, Turkey in five studies in different areas of learning while playing abroad is carried out studies in 10 areas, most preferred AR technology for mobile augmented reality technology, data collection was also used as a result of frequent use of questionnaires and success and attitude dependent variables being the most preferred dependent variables.

Keywords: augmented reality, higher education, research trends

1. Gazi Üniversitesi, Gazi Eğitim Fakültesi, Bilgisayar ve Öğretim Teknolojileri Eğitimi Bölümü, Ankara, Türkiye; https://orcid.org/0000-0002-7433-3057 2. Gazi Üniversitesi, Gazi Eğitim Fakültesi, Bilgisayar ve Öğretim Teknolojileri Eğitimi Bölümü, Ankara, Türkiye; https://orcid.org/0000-0002-6507-740X Atıf / Citation: Özaydın Aydoğdu, Y. \& Eryılmaz, S. (2019). Yükseköğretim Kurumlarında Artııılmış Gerçeklik Uygulamalarına Yönelik Yapılmış Araştırmaların İncelenmesi. Kastamonu Education Journal, 27(5), 2129-2141. doi:10.24106/kefdergi.3381 


\section{Extended Abstract}

Introduction: The aim of this study was to evaluate the work done in Turkey and abroad on augmented reality in higher education. In this direction, the methods which are used in the studies, what are the sample sizes used, which learning areas are used, what are the augmented reality technologies used, what data collection tools are used and the dependent variables are examined.

Method: In this study, descriptive survey model is used. Searches have been made in Eric, Academic Search Complete, ULAKBIM databases and YÖK thesis scanning engine using the augmented reality, augmented reality and higher education keywords in Turkish and English. As a result of the searches, 59 studies have been reached and 55 of these studies have been accessed. 48 of them are articles, four of them are master's thesis and tree of them are doctoral thesis. Eric and Academic Search Complete studies has been identified foreign articles which created by foreign authors. Eric and Academic Search Complete studies which created from Turkish authors and studies on ULAKBIM and YÖK thesis scanning engine has been identified Turkish articles. Eleven of the articles reviewed were excluded from the study due to different reasons such as being excluded from the subject, being excluded from the higher education target group, taking part as both a doctoral dissertation and an article, taking part in two different databases and being in Spanish.

Results: According to research questions most of the studies in Turkey regarding the research methods followed in the results of investigations conducted by the mixed $(n=6,55 \%)$ method is used, at least qualitative $(n=1$, $9 \%)$ was observed that the method used. In research carried out abroad most quantitative $(n=12,37 \%)$ research method is used, characterizes at least the abroad as in Turkey $(n=4,12 \%)$ was concluded using research methods. When the findings about the sample sizes used in the studies examined; Turkey is the most preferable sample size from 30 to $100(f=7)$ located, as in Turkey Studies abroad the most preferred sample size ranges from 30 to 100 ( $f$ $=12$ ) revealed that among the values. When the findings related to the learning areas where the augmented reality studies are conducted are examined; in Turkey, where most of augmented reality technology used in the field of language education, the least preferred fields were science education $(f=1,11,11 \%)$ and teaching education $(f=1$, $11,11 \%)$. Looking at the studies abroad, it was observed that the technology was mostly used in the field of engineering education $(f=5,20,83 \%)$. In addition, Turkey also study abroad compared to that of the work done in less space, the study concluded that numerically less. When the results for augmented reality technology used in these studies examined Turkey $(f=5,56 \%)$ and abroad $(f=18,72 \%)$ was the most preferred augmented reality technology proved to be mobile. According to the findings of the data collection tools used; Turkey $(f=6,40 \%)$ and abroad $(f=$ $13,39.39 \%)$ it was concluded that the most preferred data collection tools are surveys. One of the least preferred data collection tools in both categories is the cognitive load scale (Turkey, $f=1, \% 6,67$; abroad, $f=1, \% 3,03$ ). Considering the findings for the dependent variables examined; the most studied dependent variables has been shown attitudes towards the technology used $(f=9)$ in Turkey, in abroad it is level of success $(f=13)$.

As a result, the abroad studies compared Turkish studies, the augmented reality research has been shown to be more in abroad. It is concluded that, in both categories, qualitative, quantitative, mixed and literature scans are included, the most preferred sample size is between 30-100, abroad studies are carried out for more learning areas than Turkish studies, mobile augmented reality technologies are the most preferred AR technology, surveys are the most preferred data collection tool in both categories, attitude dependent variable was examined most in Turkey and success dependent variable was examined most in abroad. 


\section{Giriş}

Eğitimde de materyal kullanımı yapılan eğitimin etkililiğini ve verimliliğini artırması açısından büyük önem taşımaktadır. Eğitimde, belirli hedefler çerçevesinde kullanılan materyallere genel olarak öğretim teknolojileri adı verilmektedir. Öğretim teknolojileri, öğrenme ve etkileşim ile ilgili araşttrmalar sonucuna göre, daha etkili öğretimin sağlanması amacıyla maddi kaynaklar ve insan unsurunun birlikte kullanımı ile öğretme sürecinin belirli hedefler çerçevesinde tasarlanması, uygulanması ve değerlendirilmesi olarak tanımlanmaktadır (Reiser \& Gagné, 1983; Yalın, 2000). Gelişen yeni teknolojilerin çoğu öğrenci ilgisini çekme, aktif katlımı sağlama ve motivasyon artırma özelliklerinden dolayı eğitim-öğretim alanında kullanılmaktadır (Kreijns, Van Acker, Vermeulen, \& Van Buuren, 2013; Shen, Liu, \& Wang, 2013). Öğretim amaçılı kullanılan bu teknolojilerden biri de artırılmış gerçeklik (AG) teknolojisidir.

Artrıımış gerçeklik teknolojisi, taşınabilir teknolojilerin yaygınlaşması ve sağladıkları avantajlardan dolayı önem kazanan bir teknolojidir (Sin \& Zaman, 2010; Tian, Endo, Urata, Mouri, \& Yasuda, 2014; Tomi \& Rambli, 2013; Zarzuela, Pernas, Martínez, Ortega, \& Rodríguez, 2013). Artıılmış gerçeklik, yaşamımızda bulunan gerçek nesneler üzerine sanal medyaların (resim, ses, animasyon vb.) eklenmesi ile ortaya çıkan teknolojidir (Delello, 2014; Höllerer \& Feiner, 2004; Pérez-López \& Contero, 2013; Zhou, Duh, \& Billinghurst, 2008). Azuma (1997)'ye göre artırılmış gerçeklik teknolojilerinde olması gereken üç temel özellik bulunmaktadır. Bunlar; sanal nesneler ve gerçek dünyanın birleştirilmiş olması, sanal nesneler ve gerçek dünyanın eş zamanlı olarak sunulması ve üç boyutun kullanılmasıdır.

Artırılmış gerçekliğin eğitim, askeriye, eczacılık, mühendislik, turizm ve reklam gibi alanlarda kullanıldığı görülmekte$\operatorname{dir}$ (Wu, Lee, Chang, \& Liang, 2013). Artıılmış gerçeklik teknolojilerinin özel ekipmanlar gerektirmemesi hızla yayılmasını sağlamıştır. Öğretimde AG teknolojisi ilk kullanıldı̆ıında başa monte edilen, eğitime maddi olarak yük getiren araçlar gerektirmiştir. Ancak günümüzde teknolojinin gelişimi ile bilgisayarlarda ve mobil cihazlarda herhangi bir ekipman gerektirmeden kullanılabilmektedir (Sirakaya \& Alsancak Sirakaya, 2018). AG, öğrencilerin özelleştirilmiş bir aygıt olmadan gerçek dünyada görmeleri mümkün olmayan olayları görebilmelerine imkân sağlayan aktivitelerde etkili olabilmektedir (Bacca, Baldiris, Fabregat, \& Graf, 2014). Bununla birlikte artrılmış gerçeklik teknolojileri insanlar için riskli olan eğitimlerde farklı bağlamlar açısından etkililiğin sağlanması amaçı da kullanılabilmektedir. Bu teknolojiler insan hayatının büyük önem taşıdığı tıp alanındaki riskli ameliyatların bir pratiğini daha düşük maliyetlerle sağlayabileceği, sanal nesnelerin bir ormana giydirilmesi ile riskli grupta yer alan orman yangın iş̧ilerinin eğitilmesi gibi riskli eğitim gruplarında da kullanılabilmektedir. Bu açıdan düşünüldüğünde artırımış gerçeklik uygulamaları birçok farklı bağlamda kullanılabilmektedir.

Arthrımış gerçeklik teknolojileri eğitimde ise farklı amaçlar için kullanılmaktadır. AG eğitimde; eğitici kartlar, ders kitapları, hikâye kitapları ve çizgi romanlar gibi araçlarla müfredat destekleyici olarak, el kitabı ve broşür gibi araçlarla rehberlik ve tanıtım yapmak maksatlı, eğitsel oyun, eğitim gezisi ve alıştrma yapmak amaçı kullanılmaktadır (Çetinkaya \& Akçay, 2013). AG teknolojileri eğitimde öğrencilerin metinler, videolar ve resimler gibi tamamlayıcı unsurlar kullanılarak gerçek dünyada gerçekçi keşifler yapmasına olanak sunmaktadır (Dede, 2009). Öğrencinin gerçek dünyada kullanımı riskli olan kimya laboratuvarında deney yapmak gibi bilimsel fenomenleri deneyimlemesinde AG teknolojileri firsat sağlamaktadır (Wu vd., 2013).

Artırılmış gerçeklik uygulamalarının eğitimde kullanılmasının birçok avantajı vardır. Bunlar; başarıyı artırması (Chiang, Yang, \& Hwang, 2014), öğrenmeyi kolaylaştrrması (Ivanova \& Ivanov, 2011; Kaufmann, 2003; Kerawalla, Luckin, Seljeflot, \& Woolard, 2006; Rosenbaum, Klopfer, \& Perry, 2007; Shelton \& Hedley, 2002; Yoon, Elinich, Wang, Steinmeier, \& Tucker, 2012), tehlikeli deneylerin güvenli ortamlarda yapılmasını sağlaması (Wojciechowski \& Cellary, 2013), motivasyonu artrrması (Delello, 2014; Fleck \& Simon, 2013; ibili \& Şahin, 2013; Kerawalla vd., 2006), uzamsal yeteneklerin gelişmesini sağlaması (Medicherla, Chang, \& Morreale, 2010; Shelton \& Stevens, 2004), kavram yanılgılarının giderilmesi (Shelton \& Hedley, 2002; Tian vd., 2014), öğrenme de kalıcılığı sağlaması (Pérez-López \& Contero, 2013), derse olan ilgiyi artırması (Somyürek, 2014; Tomi \& Rambli, 2013), öğrenci katılımını sağlaması (Cai, 2013; Delello, 2014; Liu \& Tsai, 2013), olumlu tutum geliştirmeyi sağlaması (Lu \& Liu, 2015), mekânsal becerileri geliştirmesi (Ho, Chung, \& Lin, 2012), işbirlikli öğrenmeyi sağlaması (Han, Jo, Hyun, \& So, 2015), eğlenirken öğrenmeyi sağlaması (Tomi \& Rambli, 2013; Yilmaz, 2016) ve bilişsel yükü azaltmasıdır (Küçük, Kapakin, \& Göktaş, 2016). Artırımış gerçeklik teknolojilerinin eğitimde kullanım avantajlarının yanı sıra, kullanım sırasında karşılaşılan teknik problemler yaşanan en sık dezavantajdır (Lu \& Liu, 2015). Ayrıca artııımış gerçeklik uygulamalarının kullanıldığı sınıflarda, normal sınıflara göre daha fazla zaman gerektirmesi de dezavantajları arasındadır (Gavish vd., 2015). Ancak artırımış gerçeklik kullanılarak yapılan eğitimlerdeki avantajlar göz önünde bulundurulduğunda teknik dezavantajların giderilebilecek problemler olduğu düşünülmektedir. Bunun yanı sıra dezavantajlardan olan zaman bağlamının da normal sınıflara oranla artırılmış gerçeklik kullanılan sınıflarda kavram yanılgılarının az olması ve öğrenmeyi kolaylaştırması gibi sonuçlar göz önünde bulundurulduğunda etkililik ve verimlilik açısından çok büyük problemlere sebep olmayacağı düşünülmektedir. 
Artrıımış gerçeklik teriminin, literatür incelendiğinde sanal gerçeklik ile çokça karıştrıldığı görülmektedir. Artrılmış gerçeklik var olan ortamlar üzerine üç boyutlu sanal nesnelerin giydirilmesi, sanal gerçeklik ise öğrenenin tamamen sanal bir ortamda bulunmasıdır. Artıılmış gerçeklik teknolojisi eğitimde birçok farklı alanda kullanılmasının yanı sıra okul öncesi, ilkokul, orta okul, lise gibi farklı öğrenme seviyelerinde de kullanılmaktadır (Sirakaya \& Alsancak Sirakaya, 2018). AG teknolojisinin kullanıldığı bir diğer seviye de yükseköğretimdir. Yükseköğretim kurumları, mesleki yaşama ve hayata bireyi hazırlayan (Bergan \& Damian, 2010), ülke ekonomisine katkı sağlayan (Ramsden, 1991) önemli kuruluşlardandır. Ülke ekonomisi ve geleceği açısından bu kurumlardaki bireylerin eğitimi büyük önem taşımaktadır. Yükseköğretim kurumlarındaki öğrencilerin öğrenmelerinde özellikle karmaşık bilgilerin öğreniminde AG teknolojileri büyük avantaj sağlamaktadır (Lee, 2012; Liarokapis, White, \& Lister, 2004). Yükseköğretim kurumlarında sıradan eğitim ile yapılan karmaşık bilgilerin öğretiminde öğrenci aşırı yüklenme yaşayacakken, AG ortamlarının sunduğu deneyim ve farklı medyalar ile destek verilmesi bilgilerin anlaşılmasında kolaylık sağlayacaktır (Wu vd., 2013). Karmaşık bilgi ve becerilerin transferinin sağlanması, başka bir deyişle mesleki yaşama aktarılması yükseköğretim kurumlarının belirlemiş olduğu öğrenme hedeflerinden biridir. Bireylerin öğrendikleri bilgileri gerçek hayata geçirmeleri konusunda uygulamalı eğitim sağladığından dolayı artırılmış gerçeklik uygulamaları gibi teknolojilerin yükseköğretimde kullanımı büyük önem taşımaktadır. Bu durumdan yola çıkarak araştırmanın amacı, yükseköğretim kurumlarında yapılan artırılmış gerçeklik uygulamalarının Türkiye ve yurt dışında yapılan çalışmalar açısından karşılaştrılması olarak belirlenmiştir. Bu amaç doğrultusunda araştırma soruları aşağıdaki şekilde oluşturulmuştur.

Türkiye ve yurt dışında yükseköğretim kurumlarına yönelik yapılan artırılmış gerçeklik çalışmalarında,

- Hangi yöntemler izlenmiştir?

- Kullanılan örneklem büyüklükleri nelerdir?

- Hangi öğrenme alanları kullanılmıştır?

- Kullanılan AG (artrıımış gerçeklik) teknolojileri nelerdir?

- Kullanılan veri toplama araçları nelerdir?

- Incelenen bağımlı değişkenler nelerdir?

\section{Yöntem}

\section{Araştırmanın Modeli}

Bu çalışmada betimsel tarama modeli kullanılmıştr. Betimsel tarama, incelenen konu ile ilgili mevcut durumu olduğu haliyle ele almadır (A. Şimşek vd., 2009). Yapılan araştırma Türkiye ve yurt dışında artııımış gerçeklik araştırmalarındaki durumu ortaya çıkarmak amaçı yapıldığından bu model kullanılmıştır. Bu model çerçevesinde veri toplama işlemi belge incelemesi ile yapılmıştr. Belge inceleme yöntemi yazılı kaynakların belirlenen amaçlar doğrultusunda analiz edilmesi anlamına gelmektedir (H. Şimşek \& Yıldırım, 2011). Bu araştırmada Eric, Academic Search Complete, ULAKBiM veri tabanları ve YÖK tez tarama motoru kullanılmıştr. Yükseköğretimde yapılmış olma kriteri ile veri tabanlarında var olan tüm çalışmalar kullanıımıştır, toplamda 59 çalışmaya ulaşılmıştır. Bulunan çalışmalar "kullanılan araştırma yöntemleri, örneklem büyüklükleri, öğrenme alanları, kullanılan AG teknolojileri, veri toplama araçları ve bağımlı değişkenler" açısından incelenmiştir.

\section{Veri Toplama Süreci}

Bu araştırmada, yükseköğretimde artııımış gerçeklik kullanımı alanında yürütülen araştırmalara Eric, Academic Search Complete, ULAKBIM veri tabanlarından ve YÖK tez tarama motorundan erişilmiştir. Bu doğrultuda, Tablo 1' de görüldüğü gibi Eric ve Academic Search Complete veri tabanlarında bulunan 47 makaleye, ULAKBiM veri tabanında bulunan bir makaleye ve YÖK tez tarama motorunda bulunan 11 teze ulaşılmıştır. Bu taramada yapılan çalışmaların anahtar kelimelerinde tarama yapılmıştır. Taramalar "artııımış gerçeklik, yükseköğretimde artırılmış gerçeklik, augmented reality ve augmented reality in higher education" anahtar kelimeleri kullanılarak yapılmıştır.

Yürütülen çalışma, 2015-2018 yıllarında yapılan araştırmalarla sınırlandırılmıştır. Bu yıllar arasında yapılan taramalar sonucunda toplam 59 çalışmaya ulaşılmıştır. Ulaşılan çalışmalarda makalelerin tamamına erişilmiştir. Ancak yazar tarafindan erişimi sınırlandırılmış üç yüksek lisans, bir doktora tezine erişilememiştir (Tablo 1). 
Tablo 1. Çalışma kapsamında taranan veri tabanları, arama motorları ve bulunan kaynak sayıları

\begin{tabular}{lccc}
\hline Veri Tabanları, Arama Motorları & Kaynak Türü & Bulunan Kaynak Sayısı & Erişilebilen Kaynak Sayısı \\
Eric & Makale & 47 & 47 \\
Academic Search Complete & & 1 & 1 \\
ULAKBiM & Yüksek Lisans Tezi & 7 & 4 \\
YÖK tez tarama motoru & Doktora Tezi & 4 & 3 \\
\hline Toplam & & 59 & 55 \\
\hline
\end{tabular}

Erişilen kaynakların incelenmesi sonucu kaynaklardan ikisinin İspanyolca yazılmış olması, bir doktora tezinin hem tez hem de makale olarak veri tabanlarında yer alması, bir makaleye hem Eric hem de Academic Search Complete veri tabanında erişilmesi, üç makalenin artırılmış gerçeklik konusu dışında kalması, bir makale, iki yüksek lisans tezi ve bir doktora tezinin hedef kitle olarak yükseköğretim dışında olmasından dolayı 11 yayın bu çalışma dışında tutulmuştur. Yapılan incelemeler sonucu çalışmaya dahil edilen araştırmaların künyelerine, çalışma tiplerine ve yayın kaynaklarına yönelik bilgiler Tablo 2'de verilmiştir.

Tablo 2. Çalışmaya dahil edilen yayınlara yönelik bilgiler

\begin{tabular}{|c|c|c|c|}
\hline No & İncelenen çalışmalar & Çalışma tipi & Yayınlandığı kaynak \\
\hline 1 & Garrett, B. M., Jackson, C., \& Wilson, B. (2015) & Makale & Interactive Technology and Smart Education, \\
\hline 2 & $\begin{array}{l}\text { Martín-Gutiérrez, J., Fabiani, P., Benesova, W., } \\
\text { Meneses, M. D., \& Mora, C. E. (2015) }\end{array}$ & Makale & Computers in Human Behavior \\
\hline 3 & $\begin{array}{c}\text { Akçayır, M., Akçayır, G., Pektaş, H. M., \& Ocak, M. } \\
\text { A. (2016) }\end{array}$ & Makale & Computers in Human Behavior \\
\hline 4 & Ke, F., \& Hsu, Y. C. (2015) & Makale & The Internet and Higher Education \\
\hline 5 & $\begin{array}{l}\text { Tirado-Morueta, R., Sánchez-Herrera, R., } \\
\text { Márquez-Sánchez, M. A., Mejías-Borrero, A., \& } \\
\text { Andujar-Márquez, J. M. (2018) }\end{array}$ & Makale & European Journal of Engineering Education \\
\hline 6 & Hellermann, J., Thorne, S. L., \& Fodor, P. (2017) & Makale & Classroom Discourse \\
\hline 7 & Cheng, K. H. (2017) & Makale & Australasian Journal of Educational Technology \\
\hline 8 & $\begin{array}{l}\text { Martin-Gonzalez, A., Chi-Poot, A., \& Uc-Cetina, V. } \\
\text { (2016) }\end{array}$ & Makale & $\begin{array}{l}\text { Innovations in Education and Teaching Internatio- } \\
\text { nal }\end{array}$ \\
\hline 9 & $\begin{array}{l}\text { Carbonell Carrera, C., \& Bermejo Asensio, L. A. } \\
\text { (2017). }\end{array}$ & Makale & Journal of Geography in Higher Education \\
\hline 10 & $\begin{array}{l}\text { Sungkur, R. K., Panchoo, A., \& Bhoyroo, N. K. } \\
\text { (2016) }\end{array}$ & Makale & Interactive Technology and Smart Education \\
\hline 11 & $\begin{array}{l}\text { Harley, J. M., Poitras, E. G., Jarrell, A., Duffy, M. C., } \\
\text { \& Lajoie, S. P. (2016) }\end{array}$ & Makale & $\begin{array}{l}\text { Educational Technology Research and Develop- } \\
\text { ment }\end{array}$ \\
\hline 12 & $\begin{array}{l}\text { Naaji, A., Mustea, A., Holotescu, C., \& Herman, C. } \\
\text { (2015) }\end{array}$ & Makale & $\begin{array}{l}\text { Broad Research in Artificial Intelligence and } \\
\text { Neuroscience }\end{array}$ \\
\hline 13 & $\begin{array}{l}\text { Koutromanos, G., Sofos, A., \& Avraamidou, L. } \\
\text { (2015) }\end{array}$ & Makale & Educational Media International \\
\hline 14 & $\begin{array}{c}\text { Chang, Y. L., Hou, H. T., Pan, C. Y., Sung, Y. T., \& } \\
\text { Chang, K. E. (2015) }\end{array}$ & Makale & Journal of Educational Technology \& Society \\
\hline 15 & $\begin{array}{c}\text { Muñoz-Cristóbal, J. A., Prieto, L. P., Asensio-Pérez, } \\
\text { J. I., Martínez-Monés, A., Jorrín-Abellán, I. M., \& } \\
\text { Dimitriadis, Y. A. (2015) }\end{array}$ & Makale & Educational Technology \& Society \\
\hline 16 & Rizov, T., \& Rizova, E. (2015) & Makale & $\begin{array}{l}\text { International Journal of Cognitive Research in } \\
\text { Science, Engineering and Education }\end{array}$ \\
\hline 17 & Frydenberg, M., \& Andone, D. (2018) & Makale & Journal of Information Systems Education \\
\hline 18 & Solak, E., \& Cakir, R. (2015) & Makale & Journal of Educators Online \\
\hline 19 & Shirazi, A., \& Behzadan, A. H. (2015) & Makale & Advances in Engineering Education \\
\hline 20 & McMahon, D., Cihak, D. F., \& Wright, R. (2015) & Makale & Journal of Research on Technology in Education \\
\hline 21 & Joan, D. R. (2015) & Makale & Journal of Educational Technology \\
\hline 22 & $\begin{array}{l}\text { Woods, T. L., Reed, S., Hsi, S., Woods, J. A., \& } \\
\text { Woods, M. R. (2016) }\end{array}$ & Makale & Journal of Geoscience Education \\
\hline
\end{tabular}




\begin{tabular}{|c|c|c|c|}
\hline No & İncelenen çalışmalar & Çalışma tipi & Yayınlandığı kaynak \\
\hline 23 & $\begin{array}{r}\text { Li, K. C., Tsai, C. W., Chen, C. T., Cheng, S. Y., \& Heh, } \\
\text { J. S. (2015) }\end{array}$ & Makale & Universal Journal of Educational Research \\
\hline 24 & $\begin{array}{c}\text { Juan, M. C., Alexandrescu, L., Folguera, F., \& } \\
\text { García, I. G. (2016) }\end{array}$ & Makale & Digital Education Review \\
\hline 25 & Cabero Almenara, J., \& Barroso, J. (2016). & Makale & $\begin{array}{l}\text { Journal of New Approaches in Educational Rese- } \\
\qquad \text { arch }\end{array}$ \\
\hline 26 & Bicen, H., \& Bal, E. (2016) & Makale & $\begin{array}{l}\text { World Journal on Educational Technology: Current } \\
\text { Issues }\end{array}$ \\
\hline 27 & Fernandez, M. (2017) & Makale & Higher Learning Research Communications \\
\hline 28 & Akgün, Ö. E., İstanbullu, A., \& Avci, Ş. K. (2017) & Makale & Journal of Education and Training Studies \\
\hline 29 & Özcan, M. F., Özkan, Â., \& Sahin, N. (2017) & Makale & Universal Journal of Educational Research \\
\hline 30 & Chandrasekera, T., \& Yoon, S. Y. (2018) & Makale & Design and Technology Education \\
\hline 31 & Sirakaya, M., \& Alsancak Sirakaya, D. (2018) & Makale & $\begin{array}{l}\text { Malaysian Online Journal of Educational Techno- } \\
\qquad \operatorname{logy}\end{array}$ \\
\hline 32 & Küçük, S., Kapakin, S., \& Göktaş, Y. (2016) & Makale & Anatomical sciences education \\
\hline 33 & $\begin{array}{c}\text { Min, W., Jiang, S., Wang, S., Xu, R., Cao, Y., Her- } \\
\text { ranz, L., \& He, Z. (2017) }\end{array}$ & Makale & Multimedia Systems \\
\hline 34 & Wójcik, M. (2016) & Makale & Education and Information Technologies \\
\hline 35 & Taçgın, Z., \& Arslan, A. (2017) & Makale & Education and Information Technologies \\
\hline 36 & Kwong, T., Wong, E., \& Yue, K. (2017) & Makale & Technology, Knowledge and Learning \\
\hline 37 & $\begin{array}{l}\text { Ferrer-Torregrosa, J., Torralba, J., Jimenez, M. A., } \\
\text { García, S., \& Barcia, J. M. (2015) }\end{array}$ & Makale & Journal of Science Education and Technology \\
\hline 38 & Liou, W. K., Bhagat, K. K., \& Chang, C. Y. (2016) & Makale & Journal of Science Education and Technology \\
\hline 39 & $\begin{array}{l}\text { Sweeney, S. K., Newbill, P., Ogle, T., \& Terry, K. } \\
\text { (2018) }\end{array}$ & Makale & Tech Trends \\
\hline 40 & Wang, Y. H. (2017) & Makale & Journal of Computer Assisted Learning \\
\hline 41 & Küçük, S., Kapakin, S., \& Göktaş, Y. (2015) & Makale & Journal of Higher Education \& Science \\
\hline 42 & Doğan, Ö. (2016) & Yüksek Lisans Tezi & YÖK \\
\hline 43 & Baysan, E. (2015) & Yüksek Lisans Tezi & YÖK \\
\hline 44 & Küçük, S. (2015) & Doktora Tezi & YÖK \\
\hline
\end{tabular}

\section{Verilerin Analizi}

Erişilen kaynakların incelenmesinde uzman görüşleri alınarak bir sınıflandırma formu oluşturulmuştur. Sınıflandırma formu artırımış gerçeklik çalışmalarında; kullanılan araştırma yöntemlerine, örneklem büyüklüklerine, öğrenme alanlarına, kullanılan AG teknolojilerine ve veri toplama araçlarına göre sınıflandırmayı içermektedir. Araştırmaların kodlanmasında öncelikle yazarlar ayrı ayrı kodlamalar yapmışlardır. Yapılan kodlamalar karşılaştıılarak fikir ayrılığı yaşanan çalışmalar tekrar incelenmiş ve kodlamaya son hali verilmiştir. Yapılan incelemeler sonucunda elde edilen verilerin frekans ve yüzde hesaplamaları yapılmıştr. Bu hesaplamalara yönelik grafik ve tablolar oluşturulmuştur.

\section{Bulgular ve Yorum}

Bu başlık altında, belirlenen araştırma soruları doğrultusunda elde edilen bulgulara yer verilmiştir. Çalışmada Eric ve Academic Search Complete veri tabanlarında erişilen yabancı yazarlı makaleler yurt dışında yapılan çalışmalar, ULAKBiM ve YÖK tez tarama motorunda erişilen çalışmalar ile Eric ve Academic Search Complete veri tabanlarında erişilen Türk yazarlı çalışmalar ise Türkiye de yapılan çalışmalar olarak incelenmiştir. Araştırmacılar tarafindan yapılan incelemeler sonucunda araştırma soruları çerçevesinde Türkiye ve yurt dışında yapılan çalışmalar karşılaştrılmıştır.

Erişilebilen araştırmalar incelendiğinde $(n=55)$ bu araştırmalardan üç tanesinin artırılmış gerçeklik konusu dışında kaldığı sonucuna ulaşılmıştı. Ayrıca araştırmalardan dört tanesinin belirlenen yükseköğretim hedef kitlesinin dışında kaldığı görülmüştür. Araştırmalardan biri tarama yapılan veri tabanlarında hem doktora tezi hem de makale olarak yer almaktadır. Bu çalışmada doktora tezi dikkate alınmıştr. Tarama yapılan Eric ve Academic Search Complete veri tabanlarında aynı araştırma iki defa yer almaktadır, bundan dolayı bu araştırma tek bir çalışma olarak değerlendirilmiştir. Ayrıca incelenen araştırmalardan iki tanesi İspanyolca yazıldığından dolayı bu araştırmaya dahil edilememiştir. Sonuç olarak bu araştırma kapsamında yükseköğretimde artırımış gerçeklik üzerine Eric ve Academic Search Complete veri tabanları, ULAKBIM ve YÖK tez tarama motorunda yer alan 44 çalışma ele alınmış ve bu çalışmalara yönelik bulgulara 
yer verilmiştir.

\section{İncelenen çalışmalarda izlenen araştırma yöntemlerine ilişkin bulgular.}

Türkiye ve yurt dışında yapılan çalışmalarda kullanılan araştırma yöntemlerine yönelik eğilimler Şekil 1'de yer almaktadır.
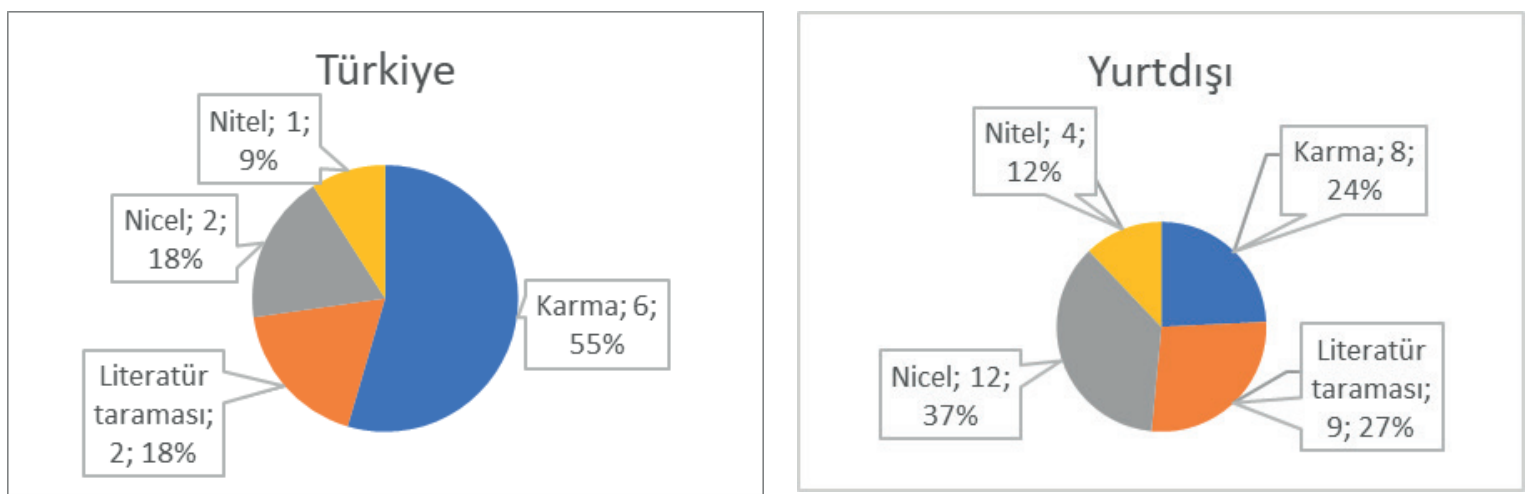

Şekil 1. Çalışmalarda izlenen araştırma yöntemlerine yönelik bulgular

Şekil 1 incelendiğinde Türkiye'de yapılan yükseköğretimde artırılmış gerçeklik çalışmalarında Karma ( $f=6, \% 55)$ araştırma yönteminin en çok tercih edilen yöntem olduğu görülmektedir. Karma araştırma yöntemi dışında Nicel araştrrma yöntemi ve literatür taramasının da Türkiye de sıklıkla ( $f=2, \% 18)$ kullanıldığı görülmektedir. Türkiye de en az tercih edilen araştırma yönteminin ise Nitel $(f=1, \% 9)$ araştırma yöntemi olduğu gözlemlenmektedir. Yurt dışında yapılan çalışmalardaki araştırma yöntemleri incelendiğinde ise en çok tercih edilen yöntemin Nicel $(f=12, \% 37)$ araştırma yöntemi olduğu görülmektedir. Yurt dışında yapılan çalışmalarda Literatür taraması ( $f=9, \% 27)$ ve Karma $(f=8, \% 24)$ araştırma yönteminin de genellikle kullanıldığı söylenebilir. Yurt dışında en az tercih edilen araştırma yöntemi ise Türkiye de olduğu gibi Nitel $(f=4, \% 12)$ araştrrma yöntemidir. Her ne kadar Türkiye'de yapılan Nitel araştırma yöntemi ile yürütülen çalışmaların sayısı az görünse de yapılan karma araştırma sayısına bakıldığında aslında nitel araştırma yönteminin nicel araştırma yöntemi gibi büyük oranda tercih ediliyor olduğu söylenebilir.

\section{İncelenen çalışmalarda kullanılan örneklem büyüklüklerine yönelik bulgular.}

Türkiye ve yurt dışında yürütülen çalışmalarda kullanılan örneklem büyüklüklerine yönelik frekans değerleri Şekil 2'de yer almaktadır.

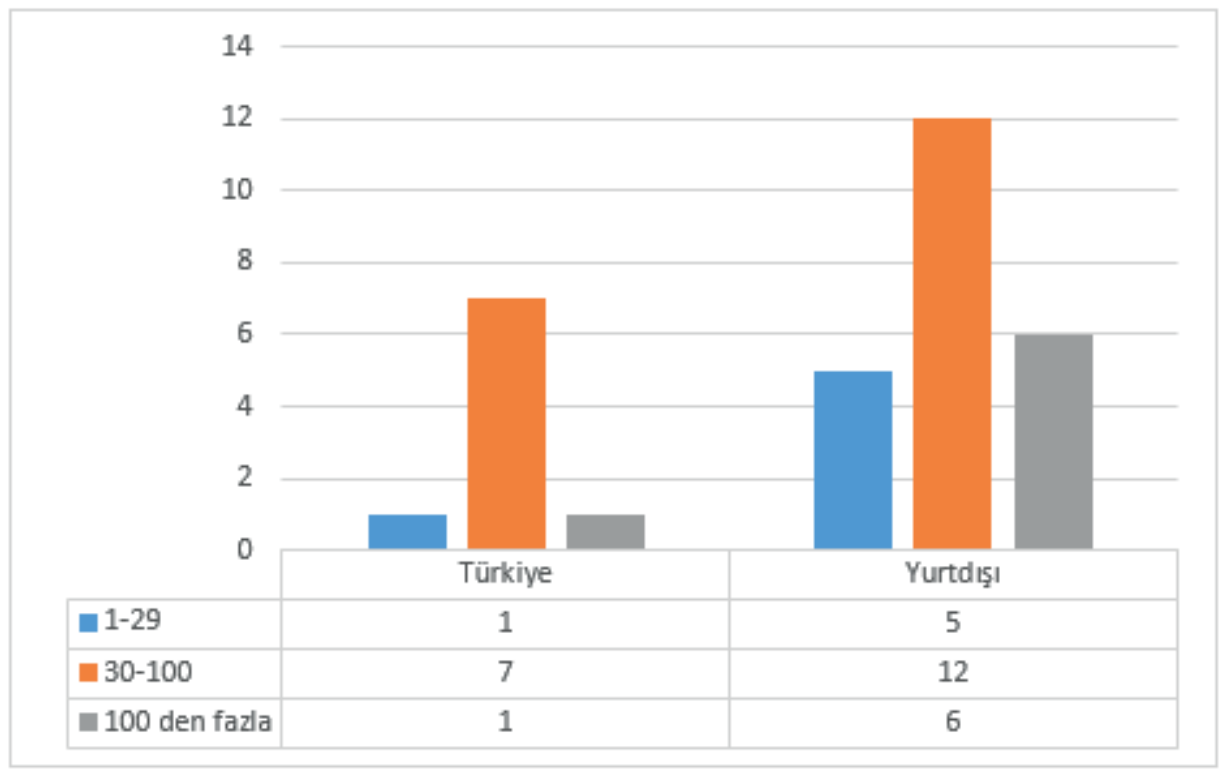

\section{Şekil 2. Örneklem büyüklüklerine yönelik bulgular}

Şekil 2 incelendiğinde Türkiye'de en çok tercih edilen örneklem büyüklükleri 30-100 ( $f=7)$ değerleri arasında yer almaktadır. 1-29 ve 100'den fazla örneklem büyüklüklerinin ise birer araştırma da tercih edildiği gözlemlenmektedir. Yurt dışında yapılan çalışmalarda da en çok tercih edilen örneklem büyüklüğü aralığı 30-100 ( $f=12$ ) arasındadır. Yurt dışında 
yapılan çalışmalarda en az tercih edilen örneklem büyüklüğü aralığının 1-29 ( $f=5$ ) olduğu, 100'den fazla örneklem büyüklüğünün ise alt çalışmada seçildiği gözlemlenmektedir. Yurt dışında 1-29 ve 100'den fazla örneklem büyüklüklerinin 30-100 aralığına göre daha az tercih edildiği görülmektedir. Her ne kadar bu aralık tercihleri 30-100 aralığına göre daha az tercih edilmiş olsa da Türkiye'de yapılan çalışmalara göre bu aralığın daha fazla olduğu gözlemlenmektedir.

\section{Artırımış gerçeklik çalışmalarının yürütüldükleri öğrenme alanlarına ilişkin bulgular.}

İncelenen çalışmaların hangi öğrenme alanında yürütüldüklerine ilişkin frekans ve yüzde değerleri Tablo 3'de yer almaktadır.

Tablo 3. Öğrenme Alanlarına Yönelik Bulgular

\begin{tabular}{lcccc}
\hline Öğrenme Alanı & \multicolumn{2}{c}{ Türkiye } & \multicolumn{2}{c}{ Yurt dışı } \\
\hline & $\mathrm{f}$ & $\%$ & $\mathrm{f}$ & $\%$ \\
\hline Bilgisayar & 2 & 22,22 & 1 & 4.17 \\
Etik & 0 & 0 & 1 & 4,17 \\
Fen bilimleri & 1 & 11,11 & 3 & 12,5 \\
Kültür & 0 & 0 & 3 & 12,5 \\
Matematik & 0 & 0 & 1 & 4,17 \\
Mühendislik & 0 & 0 & 5 & 20,83 \\
Oryantasyon & 0 & 0 & 1 & 4,17 \\
Öğretmenlik & 1 & 11,11 & 0 & 0 \\
Sosyal Bilgiler & 0 & 0 & 2 & 8,33 \\
Tıp & 2 & 22,22 & 4 & 16,67 \\
Dil Eğitimi & 3 & 33,33 & 3 & 12,50 \\
\hline Toplam & 9 & 100 & 24 & 100 \\
\hline
\end{tabular}

Tablo 3 incelendiğinde Türkiye'de yürütülen çalışmalarda en çok tercih edilen öğrenme alanının dil eğitimi ( $\mathrm{f}=3, \% 33,33$ ) olduğu görülmektedir. Türkiye'de dil eğitiminin yanı sıra bilgisayar eğitimi ve tıp eğitimi alanlarında da sıklıkla $(\mathrm{f}=2, \% 22,22)$ artırılmış gerçeklik teknolojisi yükseköğretimde tercih edilmektedir. Türkiye'de en az tercih edilen alanların ise fen bilimleri eğitimi ve öğretmenlik eğitimi ( $\mathrm{f}=1, \% 11,11)$ olduğu görülmektedir. Yurt dışında yapılan çalışmalarda ise Türkiye'deki çalışma alanlarına ek olarak etik, kültür, matematik, mühendislik, oryantasyon, sosyal bilimler eğitimi gibi alanlarda da çalıșmalar yapılmıştır. Yurt dıșında artırılmış gerçekliğin yükseköğretimde en çok kullanıldığı alanın mühendislik eğitimi ( $(\mathrm{f}=5, \% 20,83)$ olduğu gözlemlenmektedir. Mühendislik eğitiminin yanı sıra yurt dışında tıp eğitimi (f=4, \%16,67) alanında da yoğun çalışmalar yapıldı ğı söylenebilir. Ayrıca yurt dışında fen bilimleri, kültür ve dil eğitiminde $(\mathrm{f}=3, \% 12,5)$ de sıklıkla çalışmalar yapıldığı görülmektedir. Yurt dışında yapılan çalışmalar incelendiğinde Türkiye'deki çalışmaların aksine öğretmenlik eğitimi alanında yapılan bir çalışmaya rastlanılmamıştır. Tablo 3'ye göre Türkiye'de yapılan çalışmaların yurt dışında yapılan çalışmalara oranla daha az alanda yapıldığı, yapılan çalışmaların sayıca daha az olduğu söylenebilir.

\section{Artırılmış gerçeklik çalışmalarında kullanılan AG teknolojilerine yönelik bulgular.}

Türkiye ve yurt dışında yapılan yükseköğretimde artırılmış gerçeklik çalışmalarında kullanılan AG teknolojilerine göre dağılımlara yönelik frekans ve yüzde değerleri Şekil 3’de yer almaktadır.

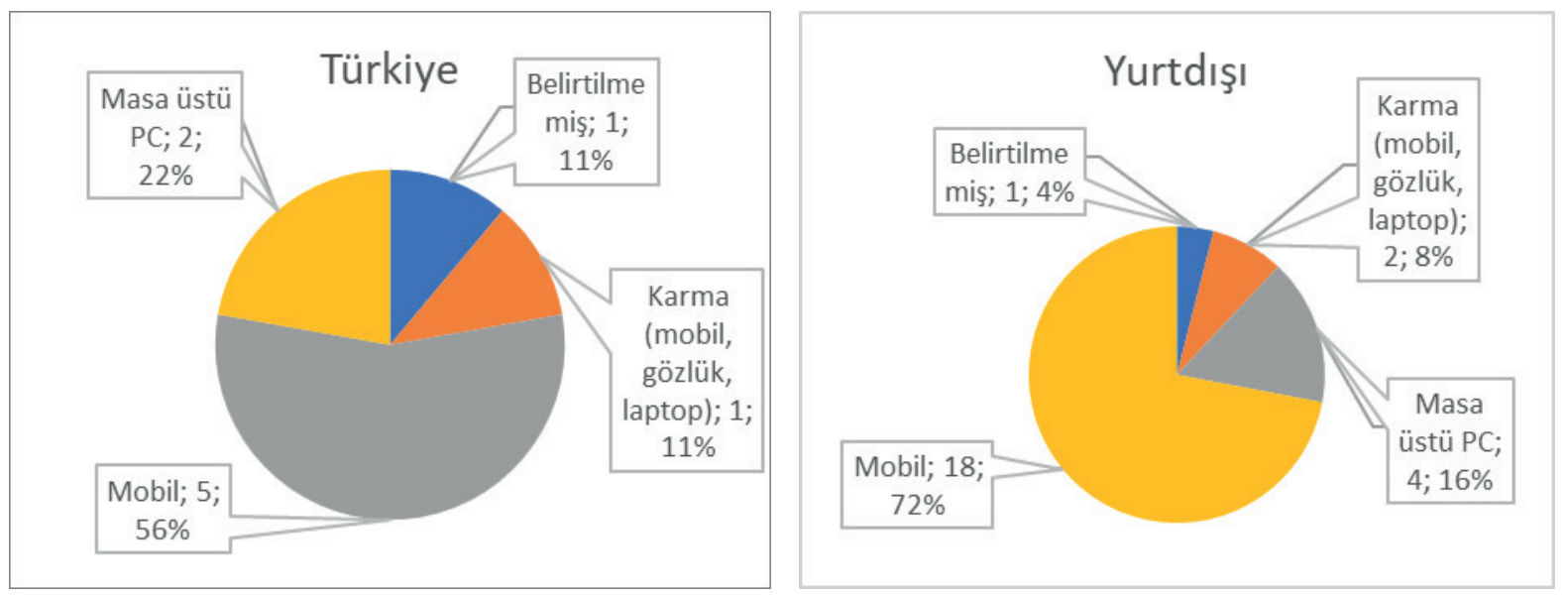

Şekil 3. Kullanılan AG teknolojilerine yönelik bulgular

Şekil 3'e göre Türkiye'de ( $f=5, \% 56)$ ve yut dışında ( $f=18, \% 72$ ) yapılan çalışmaların çoğunda en çok tercih edilen AG teknolojisinin Mobil teknoloji olduğu görülmektedir. Mobil teknolojiden sonra hem Türkiye $(f=2, \% 22)$ hem de yurt

| Kastamonu Eğitim Dergisi, 27(5), 2019 | 
dışında ( $f=4, \% 16)$ en çok tercih edilen ikinci teknolojinin ise masa üstü bilgisayar destekli Ar teknolojileri olduğu gözlemlenmektedir. Bu teknolojilerin yanı sıra Türkiye'de $(f=1, \% 11)$ ve yurt dışında $(f=2, \% 8)$ mobil, AG gözlük ve $P C$ gibi teknolojilerin desteği ile karma olarak AG teknolojilerinin kullanıldığı da görülmektedir. Ayrıca Türkiye $(f=1, \% 11)$ ve yurt dışında ( $f=2, \% 8$ ) yapılan çalışmalarda kullanılan teknolojinin belirtilmediği çalışmalar da söz konusudur.

\section{Artııımış gerçeklik çalışmalarında kullanılan veri toplama araçlarına yönelik bulgular.}

Türkiye ve yurt dışında yapılan çalışmalarda kullanılan veri toplama araçlarına yönelik frekans ve yüzde değerleri Tablo 4'te yer almaktadır.

Tablo 4. Öğrenme Alanlarına Yönelik Bulgular

\begin{tabular}{lcccc}
\hline Veri Toplama Araçları & \multicolumn{2}{c}{ Türkiye } & \multicolumn{2}{c}{ Yurt dışı } \\
\hline Anket & $\mathrm{f}$ & $\%$ & $\mathrm{f}$ & $\%$ \\
Başarı Testi & 6 & 40 & 13 & 39,39 \\
Görüşme & 3 & 20 & 9 & 27,27 \\
Gözlem Formu & 5 & 15.15 & 5 & 15,15 \\
Bilişsel Yük Ölçeği & 0 & 0 & 1 & 3,03 \\
Kullanılabilirlik Ölçeği & 1 & 6,67 & 1 & 3,03 \\
Öğrenme Stili Ölçeği & 0 & 0 & 2 & 6,06 \\
Video Kaydı & 0 & 0 & 1 & 3,03 \\
\hline
\end{tabular}

Kullanılan veri toplama araçlarının türleri çalışmaların bağımlı değişkenlerine göre değişiklik göstermektedir. Ayrıca bir çalışmadan birden fazla veri toplama aracı kullanıldığı da araştırmacılar tarafindan tespit edilmiştir. Tablo 4 incelendiğinde Türkiye ( $f=6, \% 40)$ ve yurt dışında $(f=13, \% 39,39)$ en çok tercih edilen veri toplama araçlarının anketler olduğu görülmektedir. Bu anketler çeşitli bağımlı değişkenlerin (motivasyon, algı, görüş, kullanılabilirlik gibi) ölçülmesinde kullanılmıştır. Her iki kategoride (Türkiye, $f=3, \% 20$; yurt dışı, $f=9, \% 27,27$ ) de en çok tercih edilen ikinci veri toplama aracının başarı testleri olduğu da gözlemlenmektedir. Türkiye ve yurt dışında görüşme veri toplama aracının eşit miktarda $(f=5, \% 15,15)$ kullanıldığı görülmektedir. Her iki kategoride de en az tercih edilen veri toplama araçlarından biri bilişsel yük ölçeğidir (Türkiye, $f=1, \% 6,67$; yurt dışı, $f=1, \% 3,03$ ). Ayrıca yurt dışında yapılan çalışmalarda gözlem formu ( $f=1, \% 3,03)$, kullanılabilirlik ölçekleri $(f=2, \% 6,06)$, öğrenme stili ölçeği $(f=1, \% 3,03)$ ve video kaydı verileri $(f=1, \% 3,03)$ aracılığı ile de veriler toplanmıştr.

\section{Artırılmış gerçeklik çalışmalarında incelenen bağımlı değişkenlere yönelik bulgular.}

Türkiye ve yurt dışında yapılan çalışmalarda incelenen bağımlı değişkenlere yönelik frekans değerleri Şekil 4'de sunulmaktadır.

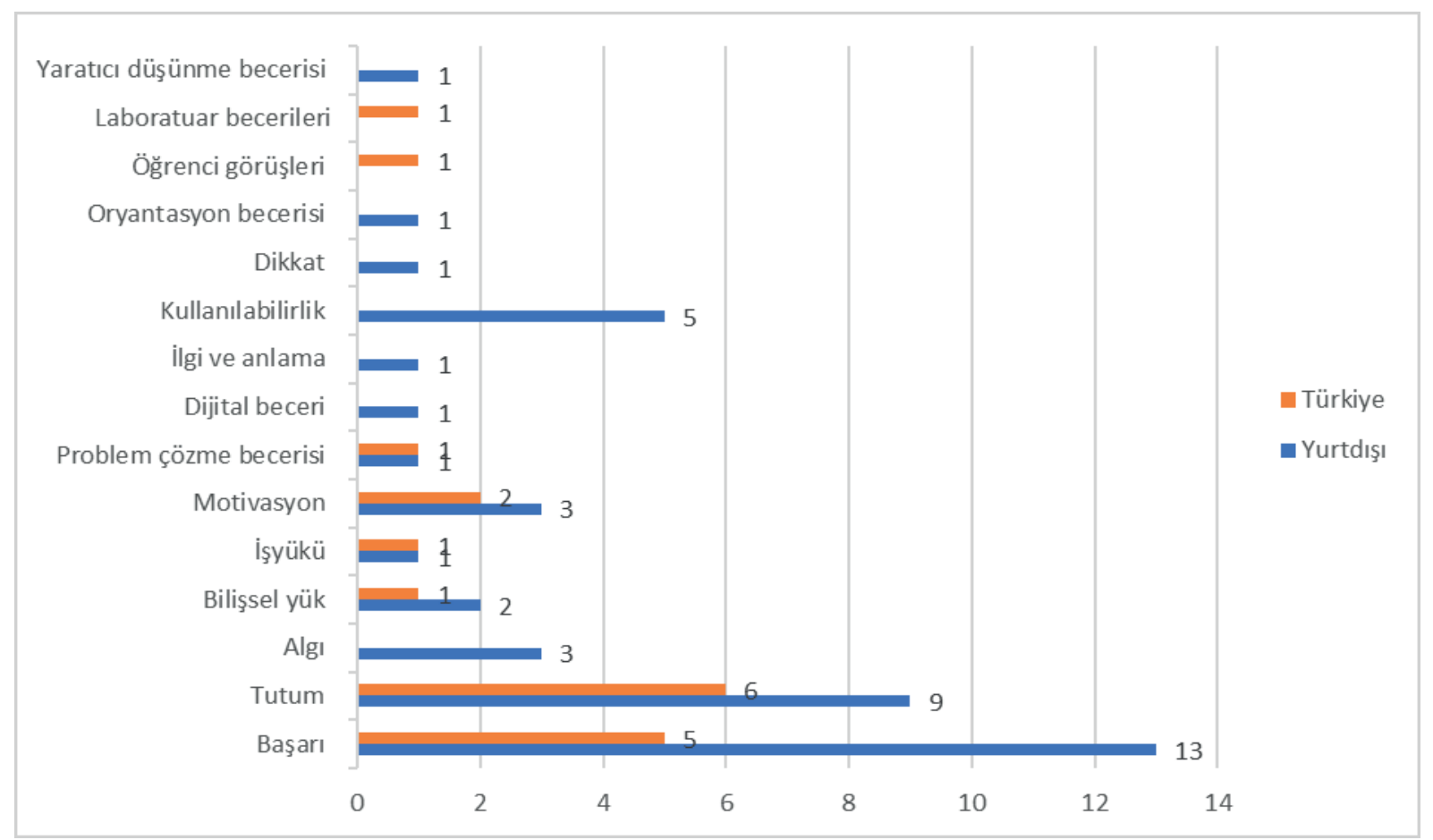

Şekil 4. Çalışmalarda incelenen bağımlı değiş̧enlere yönelik bulgular 
Yapılan çalışmalara bakıldığında incelemelerin çoğunlukla birden fazla bağımlı değişken üzerinde yapıldığı gözlemlenmiştir. Şekil 4'deki veriler incelendiğinde, Türkiye'de en çok incelenen bağımlı değişkenin yapılan eğitime ve kullanılan teknolojiye karşı tutumları $(f=9)$, yurt dışında en çok incelenen bağımlı değişkenin ise yapılan eğitim sonundaki başarı $(f=13)$ düzeyi olduğu görülmektedir. Türkiye'de ikinci en çok tercih edilen ikinci bağımlı değişkenin başarı $(f=5)$ olduğu görülür iken yurt dışında en çok tercih edilen ikinci bağımlı değişkenin tutum ( $f=9$ ) olduğu gözlemlenmektedir. Laboratuvar becerileri ve öğrenci görüşlerinin alınması bağımlı değişkenlerinin sadece Türkiye'deki çalışmalarda incelenmiş olduğu da görülmektedir. Yurt dışında ise Türkiye'deki çalışmalarda incelenmeyen yaratıcı düşünme becerisi, oryantasyon beceri, dikkat çekme, kullanılabilirlik, ilgi ve anlama, dijital beceri ve algı değişkenleri de incelenmiştir.

\section{Sonuç ve Öneriler}

Bu çalışmada Türkiye ve yırt dışında yükseköğretimde artırılmış gerçeklik teknolojilerinin kullanımı üzerine literatür taraması yapılmıştr. Bu tarama ERIC, Academic Search Complete, ULAKBIM veri tabanları ve YÖK tez tarama motorunda yapılmıştr. Veri tabanları ve tarama motorunda "artııımış gerçeklik, yükseköğretimde artırılmış gerçeklik, augmented reality ve augmented reality in higher education" anahtar kelimelerine yönelik tarama yapılmıştı. Yapılan tarama sonucunda 59 kaynağa ulaşılmış, bu kaynaklardan 55 tanesine erişilebilmiştir. Erişilen kaynaklar araştırmacılar tarafindan Türkiye ve yurt dışında; hangi araştırma yönteminin kullanıldığı, örneklem büyüklüklerinin neler olduğu, öğrenme alanlarının neler olduğu, hangi AG teknolojilerinin tercih edildiği, veri toplama araçlarının neler olduğu ve incelenen bağımlı değişkenlerin neler olduğu açısından incelenmiştir.

Yapılan incelemeler sonucunda, yurt dışında Türkiye'ye oranla artırılmış gerçeklik çalışmalarının daha fazla olduğu sonucuna ulaşılmıştır. Her iki kategoride de nitel, nicel, karma ve literatür taramalarına yer verilmiş. Sırakaya ve Alsancak Sırakaya (2018) yapmış oldukları çalışmada en çok kullanılan yöntemin nicel yöntem olduğu sonucuna ulaşmıştır. Bu çalışmada ise Türkiye'de en çok karma araştırmaların, yurt dışında ise en çok nicel araştırmaların tercih edildiği görülmüştür. Çalışmaların tamamı düşünülürse(Türkiye, Yurtdışı) en çok tercih edilen yöntemin Sırakaya ve Alsancak Sırakaya (2018) de belirttiği gibi nicel çalışmalar olduğu söylenebilir.

En çok tercih edilen örneklem büyüklüğünün hem Türkiye hem de yurt dışında 30-100 değerleri arasında olduğu, sonucuna ulaşılmıştır. Bu sonucun aksine Özdemir (2017) en çok tercih edilen örneklem büyüklüğünün 30-59 olduğu sonucuna ulaşmış ve bu durumun teknolojinin maliyetli olması ve katlımcının kullanma zorunluluğunun olması ile açıklamıştr. Ayrıca Bacca vd.(2014) yapmış oldukları literatür taramasında en çok tercih edilen örneklem büyüklüğünün 30 ile 200 arasında olduğunu belirtmişlerdir. Sırakaya ve Alsancak Sırakaya (2018) yapmış oldukları çalışmada en çok tercih edilen örneklem büyüklüğünün bu çalışmada da olduğu gibi 31-100 arasında olduğu sonucuna ulaşmışlardır.

Türkiye'de yapılan çalışmalarda artırımış gerçeklik uygulamaları kullanılarak en çok tercih edilen öğrenme alanı "Dil eğitimi" dir. Yurt dışındaki araştırmalarda ise "Mühendislik" eğitimi alanında diğer alanlara oranla daha fazla çalışma yapılmıştir. Türkiye de tercih edilen diğer alanlar; bilgisayar, fen bilimleri, öğretmenlik ve țp eğitimi iken yurt dışında bu alanlara ek olarak etik, kültür, matematik, mühendislik, oryantasyon ve sosyal bilimler eğitimlerinde kullanılmıştır. Yurt dışında daha fazla alanda bu uygulamaların kullanıımasında teknolojik gelişimlerin ve yapılan araştırma sayılarından kaynaklandığı düşünülmektedir. Artııımış gerçeklik teknolojilerinin eğitimde kullanımı ile öğrencilerde motivasyonun, dikkatin, konsantrasyonun ve memnuniyetin arttııldığı (Diegmann, Schmidt-Kraepelin, Eynden, \& Basten, 2015) göz önünde bulundurulursa daha fazla öğrenme alanında artııımış gerçeklik uygulamalarının tercih edilmesi gerektiği düşünülmektedir.

Incelenen çalışmalara bakıldığında hem Türkiye hem de yurt dışında en çok kullanılan AG teknolojisi mobil alandadır. Lee (2012) yaptı̆̆ı çalışmada AG uygulamalarının mobil alana yöneldiğini belirtmiştir. AG uygulamalarının mobil alana yönlenmesi bu teknolojilerin bireysel olarak kullanılmaya başlanılması ve bu şekilde eğitime fazladan maliyet getirmediğinden dolayı en çok tercih edilen yöntem olduğu düşünülmektedir. Ayrıca yapılan diğer literatür taraması çalışmaları incelendiğinde, bu çalışmalarda da en çok tercih edilen yöntemin mobil cihazlar kullanılarak yapılan yöntem olduğu sonucuna ulaşıımıştır (Akçayır \& Akçayır, 2017; Özdemir, 2017; Sirakaya \& Alsancak Sirakaya, 2018).

AG teknolojileri kullanılarak yapılan araştırmalarda kullanılan veri toplama araçları incelendiğinde Türkiye ve yurtdışındaki çalışmalarda en çok anketlerin tercih edildiği sonucuna ulaşılmıştı. Diğer literatür taraması çalışmaları incelendiğinde en çok tercih edilen veri toplama aracının yine anketler olduğu sonucuna ulaşıldığı görülmektedir Bacca vd., 2014; Sırakaya \& Alsancak Sırakaya, 2018). En çok tercih edilen ikinci veri toplama aracına bakıldığında Türkiye'de görüşmeler ile yurtdışında ise başarı testleri ile yapıldığı sonucuna ulaşımıştır. Bacca vd. (2014) yaptığı çalışmada en çok tercih edilen ikinci veri toplama aracının görüşmeler olduğunu, Sırakaya ve Alsancak Sırakaya (2018) ise başarı testlerinin ikinci olarak tercih edildiğini belirtmişlerdir. Bu farklılığın yapılan araştırma sayısının Türkiye'de az yurtdışında ise daha çok olduğundan kaynaklandığı düşünülmektedir. Bundan dolayı tercih edilen veri toplama araçlarının kullanım sayısına bakıldığında aslında Türkiye'de en çok tercih edilen ikinci veri toplama aracının kullanım sayısı $(n=5)$ ile yurtdı-

| Kastamonu Eğitim Dergisi, 27(5), 2019| 
şında en çok tercih edilen üçüncü veri toplama aracının kullanım sayısının $(n=5)$ eşit olduğu görülmektedir. Ayrıca yurt dışında yapılan çalışmalarda Türkiye'deki çalışmalardan farklı olarak; kullanılabilirlik ölçeği, öğrenme stili ölçeği ve video kaydı yöntemleri ile veriler toplandığı sonucuna ulaşılmıştır.

Çalışmalarda incelenen bağımlı değişkenlere bakıldığında Türkiye'de en çok tutum üzerine, yurtdışında ise başarı üzerine çalışmalar yapıldığı gözlemlenmektedir. Yapılan literatür çalışmaları incelendiğinde en çok tercih edilen bağımlı değişkenin yurtdışında yapılan çalışmalarda olduğu gibi öğrenen başarısı üzerine olduğu sonucuna ulaşılmıştı (Akçayır \& Akçayır, 2017; Bacca vd., 2014; Özdemir, 2017). Yapılan literatür taraması sonuçlarının Türkiye'deki çalışmalardan farklı olması diğer çalışmalarda Türkiye-yurtdışı ayrımının yapılmamış olmasından kaynaklandığı düşünülmektedir. En çok tercih edilen ikinci bağımlı değişkene bakıldığında ise Türkiye'de başarının yurtdışında ise tutumun olduğu sonucuna ulaşılmaktadır. Bunların yanı sıra Türkiye'de yapılan çalışmalarda kullanılan; laboratuvar becerisi değişkeninin yurtdışındaki araştırmalarda kullanılmadığı, yurtdışında kullanılan yaratıcı düşünme becerisi, oryantasyon becerisi, dikkat, kullanılabilirlik, ilgi ve anlama, dijital beceri ve algı değişkenlerinin Türkiye'de kullanılmadığı sonucuna ulaşılmıştır.

Sonraki araştırmalarda bu araştırmada taranan ERIC, Academic Search Complete, ULAKBiM veri tabanları ve YÖK tez tarama motoru dışında farklı veri tabanları da taranarak aynı yöntem ile incelemeler yapılabilir. Türkiye'deki çalışmalarda yükseköğretimde öğrenme alanı olarak etik, kültür, matematik, mühendislik, oryantasyon, sosyal bilgiler eğitimi gibi alanlar tercih edilmemiştir. Bu alanlar göz önünde bulundurularak artırılmış gerçeklik üzerine araştırmalar yürütülebilir. Aynı şekilde yurt dışında ki çalışmalarda da öğretmenlik eğitimi üzerine yapılmış araştırma yürütülmemiştir, bu alan üzerine çalışmalar yapılabilir. Türkiye'deki çalışmalarda yaratıcı düşünme becerisi, oryantasyon becerisi, dikkat çekme, kullanılabilirlik, ilgi ve anlama, dijital beceri ve algı bağımlı değişkenleri üzerine yapılmış herhangi bir çalışmaya rastlanılmamıştır. Türkiye'de çalışma yapmak isteyen araştırmacılar yükseköğretimde artırılmış gerçeklik kullanımı üzerine bu bağımlı değişkenleri göz önünde bulundurarak çalışmalar yürütebilirler.

\section{Kaynaklar}

Akçayır, M., \& Akçayır, G. (2017). Advantages and challenges associated with augmented reality for education: A systematic review of the literature. Educational Research Review, 20, 1-11.

Azuma, R. T. (1997). A survey of augmented reality. Presence: Teleoperators \& Virtual Environments, 6(4), 355-385.

Bacca, J., Baldiris, S., Fabregat, R., \& Graf, S. (2014). Augmented reality trends in education: a systematic review of research and applications. Bergan, S., \& Damian, R. (2010). Higher education for modern societies: competences and values (Vol. 15): Council of Europe.

Cai, H. (2013). Using augmented reality games as motivators for youth environmental education: An American Hart's tongue fern conservation project: State University of New York College of Environmental Science and Forestry.

Chiang, T. H.-C., Yang, S. J., \& Hwang, G.-J. (2014). An augmented reality-based mobile learning system to improve students' learning achievements and motivations in natural science inquiry activities. Educational Technology \& Society, 17(4), 352-365.

Çetinkaya, H. H., \& Akçay, M. (2013). Eğitim ortamlarında arttırılmış gerçeklik uygulamaları. Akademik Bilişim Kongresi, Antalya, $11,2015$.

Dede, C. (2009). Immersive interfaces for engagement and learning. science, 323(5910), 66-69.

Delello, J. A. (2014). Insights from pre-service teachers using science-based augmented reality. Journal of computers in education, 1(4), 295 -311.

Diegmann, P., Schmidt-Kraepelin, M., Eynden, S., \& Basten, D. (2015). Benefits of augmented reality in educational environments-A systematic literature review. Benefits, 3(6), 1542-1556.

Fleck, S., \& Simon, G. (2013). An augmented reality environment for astronomy learning in elementary grades: an exploratory study. Paper presented at the Proceedings of the 25th Conference on I'Interaction Homme-Machine.

Gavish, N., Gutiérrez, T., Webel, S., Rodríguez, J., Peveri, M., Bockholt, U., \& Tecchia, F. (2015). Evaluating virtual reality and augmented reality training for industrial maintenance and assembly tasks. Interactive Learning Environments, 23(6), 778-798.

Han, J., Jo, M., Hyun, E., \& So, H.-j. (2015). Examining young children's perception toward augmented reality-infused dramatic play. Educational Technology Research and Development, 63(3), 455-474.

Ho, P.-C., Chung, S.-M., \& Lin, Y.-H. (2012). Influences on children's visual cognition capabilities through playing 'intelligent matrix'developed by the augmented virtual reality technology. International Journal of Humanities and Arts Computing, 6(1-2), $160-171$.

Höllerer, T. H., \& Feiner, S. K. (2004). Mobile augmented reality. . In H. A. Karimi \& A. Hammad (Eds.), Telegeoinformatics: Location-Based computing and services (pp. 392-421).

İbili, E., \& Şahin, S. (2013). Artırımış Gerçeklik ile İnteraktif 3D Geometri Kitabı Yazııımın Tasarımı ve Geliştirilmesi: ARGE3D (015101)(1-8). Afyon Kocatepe Üniversitesi Fen ve Mühendislik Bilimleri Dergisi, 13(1).

Ivanova, M., \& Ivanov, G. (2011). Enhancement of learning and teaching in computer graphics through marker augmented reality technology. International Journal of New Computer Architectures and their Applications (IJNCAA), 1(1), 176-184.

Kaufmann, H. (2003). Collaborative augmented reality in education. Institute of Software Technology and Interactive Systems, Vienna University of Technology.

| Kastamonu Eğitim Dergisi, 27(5), 2019| 
Kerawalla, L., Luckin, R., Seljeflot, S., \& Woolard, A. (2006). "Making it real”: exploring the potential of augmented reality for teaching primary school science. Virtual reality, 10(3-4), 163-174.

Kreijns, K., Van Acker, F., Vermeulen, M., \& Van Buuren, H. (2013). What stimulates teachers to integrate ICT in their pedagogical practices? The use of digital learning materials in education. Computers in human behavior, 29(1), 217-225.

Küçük, S., Kapakin, S., \& Göktaş, Y. (2016). Learning anatomy via mobile augmented reality: effects on achievement and cognitive load. Anatomical sciences education, 9(5), 411-421.

Lee, K. (2012). Augmented reality in education and training. TechTrends, 56(2), 13-21.

Liarokapis, F., White, M., \& Lister, P. (2004). Augmented reality interface toolkit. Paper presented at the Information Visualisation, 2004. IV 2004. Proceedings. Eighth International Conference on.

Liu, P. H. E., \& Tsai, M. K. (2013). Using augmented-reality-based mobile learning material in EFL English composition: An exploratory case study. British Journal of Educational Technology, 44(1), E1-E4.

Lu, S.-J., \& Liu, Y.-C. (2015). Integrating augmented reality technology to enhance children's learning in marine education. Environmental Education Research, 21(4), 525-541.

Medicherla, P. S., Chang, G., \& Morreale, P. (2010). Visualization for increased understanding and learning using augmented reality. Paper presented at the Proceedings of the international conference on Multimedia information retrieval.

Özdemir, M. (2017). Artırımış Gerçeklik Teknolojisi ile Öğrenmeye Yönelik Deneysel Çalışmalar: Sistematik Bir İnceleme. Mersin Üniversitesi Eğitim Fakültesi Dergisi, 13(2), 609-632.

Pérez-López, D., \& Contero, M. (2013). Delivering educational multimedia contents through an augmented reality application: A case study on its impact on knowledge acquisition and retention. Turkish Online Journal of Educational Technology-TOJET, 12(4), 19 -28.

Ramsden, P. (1991). A performance indicator of teaching quality in higher education: The Course Experience Questionnaire. Studies in higher education, 16(2), 129-150.

Reiser, R. A., \& Gagné, R. M. (1983). Selecting media for instruction: Educational Technology.

Rosenbaum, E., Klopfer, E., \& Perry, J. (2007). On location learning: Authentic applied science with networked augmented realities. Journal of Science Education and Technology, 16(1), 31-45.

Shelton, B. E., \& Hedley, N. R. (2002). Using augmented reality for teaching earth-sun relationships to undergraduate geography students. Paper presented at the Augmented Reality Toolkit, The First IEEE International Workshop.

Shelton, B. E., \& Stevens, R. (2004). Using coordination classes to interpret conceptual change in astronomical thinking. Paper presented at the Proceedings of the 6 th international conference for the learning sciences. Lawrence Erlbaum \& Associates, Mahweh, NJ.

Shen, C.-X., Liu, R.-D., \& Wang, D. (2013). Why are children attracted to the Internet? The role of need satisfaction perceived online and perceived in daily real life. Computers in human behavior, 29(1), 185-192.

Sin, A. K., \& Zaman, H. B. (2010). Live Solar System (LSS): Evaluation of an Augmented Reality book-based educational tool. Paper presented at the Information Technology (ITSim), 2010 International Symposium in.

Sirakaya, M., \& Alsancak Sirakaya, D. (2018). Trends in Educational Augmented Reality Studies: A Systematic Review. Malaysian Online Journal of Educational Technology, 6(2), 60-74.

Somyürek, S. (2014). Öğretim sürecinde z kuşağının dikkatini çekme: artırılmış gerçeklik. Eğitim Teknolojisi Kuram ve Uygulama, 4(1), 63-80.

Şimşek, A., Özdamar, N., Uysal, Ö., Kobak, K., Berk, C., Kılıçer, T., \& Çiğdem, H. (2009). íkibinli yıllarda Türkiye'deki eğitim teknolojisi araştırmalarında gözlenen eğilimler. Kuram ve Uygulamada Eğitim Bilimleri Dergisi, 9(2), 115-120.

Şimşek, H., \& Yıldırım, A. (2011). Sosyal bilimlerde nitel araştırma yöntemleri. Ankara: Seçkin Yayıncılık.

Tian, K., Endo, M., Urata, M., Mouri, K., \& Yasuda, T. (2014). Multi-viewpoint smartphone AR-based learning system for astronomical observation. International Journal of Computer Theory and Engineering, 6(5), 396-400.

Tomi, A. B., \& Rambli, D. R. A. (2013). An interactive mobile augmented reality magical playbook: Learning number with the thirsty crow. Procedia computer science, 25, 123-130.

Wojciechowski, R., \& Cellary, W. (2013). Evaluation of learners' attitude toward learning in ARIES augmented reality environments. Computers \& Education, 68, 570-585.

Wu, H.-K., Lee, S. W.-Y., Chang, H.-Y., \& Liang, J.-C. (2013). Current status, opportunities and challenges of augmented reality in education. Computers \& Education, 62, 41-49.

Yalın, H. İ. (2000). Öğretim teknolojileri ve materyal geliştirme: Nobel Yayın Dağıtım.

Yilmaz, R. M. (2016). Educational magic toys developed with augmented reality technology for early childhood education. Computers in human behavior, 54, 240-248.

Yoon, S. A., Elinich, K., Wang, J., Steinmeier, C., \& Tucker, S. (2012). Using augmented reality and knowledge-building scaffolds to improve learning in a science museum. International Journal of Computer-Supported Collaborative Learning, 7(4), 519-541.

Zarzuela, M. M., Pernas, F. J. D., Martínez, L. B., Ortega, D. G., \& Rodríguez, M. A. (2013). Mobile serious game using augmented reality for supporting children's learning about animals. Procedia computer science, 25, 375-381.

Zhou, F., Duh, H. B.-L., \& Billinghurst, M. (2008). Trends in augmented reality tracking, interaction and display: A review of ten years of ISMAR. Paper presented at the Proceedings of the 7th IEEE/ACM International Symposium on Mixed and Augmented Reality.

| Kastamonu Eğitim Dergisi, 27(5), 2019| 